\title{
Automated injection of slurry samples in flow-injection analysis
}

\author{
M. Hulsman, M. Bos, W.E. van der Linden * \\ Mesa Research Institute, Laboratory of Chemical Analysis, Department of Chemical Technology, University of Twente, P.O. Box 217, 7500 \\ AE Enschede, Netherlands
}

Received 4 September 1995; revised 4 December 1995; accepted 8 December 1995

\begin{abstract}
Two types of injectors are described for introducing solid samples as slurries in flow analysis systems. A time-based and a volume-based injector based on multitube solenoid pinch valves were built, both can be characterized as hydrodynamic injectors. Reproducibility of the injections of dispersed solids $(\leqslant 150 \mu \mathrm{m})$ was tested with several concentrations of slurry samples up to $30 \mathrm{mg} / \mathrm{ml}$; the injected volume was $1 \mathrm{ml}$. For both injectors dye and slurry samples could be injected with good precision (relative standard deviation for the peak area less than $2 \%$ ). Peak detection was performed turbidimetrically. Data analysis and operation of the injectors were automated. The usual peristaltic pumps in flow analysis are normally not capable of handling slurries of the type investigated, therefore a valveless piston pump was used instead.
\end{abstract}

Keywords: Flow injection; Slurry samples; Automated injection

\section{Introduction}

Flow-injection analysis (FIA) systems normally require completely dissolved samples. Sample digestion is generally still carried out manually, prone to contamination and therefore often suffers from poor reproducibility. Direct injection of solid samples by the slurry approach can be advantageous. Only a few reports on this topic have been published. Slurry injection is described in combination with on-line micro-wave destruction and/or (F)AAS detection [1-5]. However, these systems are only capable of handling low concentration and small particle size slurries, whereas with a higher content a better representation of the solid sample should be obtained [2],

\footnotetext{
" Corresponding author.
}

especially in environmental analysis. The possibility of handling bigger particles can facilitate pretreatment if the necessary grinding of particles can be avoided. In some cases grinding is not even allowed e.g. at studies on absorbed components at the surface of sludge particles. The injectors described in literature are based on rotary valves, but they suffer from common problems such as clogging [1] and wear of the switching plates of the valves. The loading of the sample loops is performed manually, probably because the peristaltic pumps used are not capable of pumping slurries. One system described which actually pumps a slurry sample stream [5] was able to handle small particles $(\leqslant 20 \mu \mathrm{m})$ at low concentrations $(\leqslant 10 \mathrm{mg} / \mathrm{ml})$ only.

An interesting alternative injection method is the hydrodynamic injection (HI), as introduced by Ruzicka and Hansen [6], but to our knowledge this has not been used for slurries yet. $\mathrm{HI}$ is interesting 
because moving parts of the injector do not interfere with the actual metering of the accurate sample volume. The hydrodynamic injectors described in literature [6-9] cannot be used directly for the injection of slurries because of some specific disadvantages and operating problems:

- the first hydrodynamic injector of Ruzicka and Hansen [6] requires two equal flow-rates, which is hard to obtain [7] and during the loading cycle the carrier flow through the reaction coil is stopped which makes it difficult to realize a reproducible operation;

- to our knowledge no practical experience with a second type of hydrodynamic injector proposed by Ruzicka and Hansen [8] is described. Here the reproducibility of injections depends heavily on the timing of the pump control and the fact that the pump is placed after the detector makes this system sensitive to degassing solutions, especially in the case of long residence times as in the case of extensive on-line treatment of slurry samples $[1,2]$;

- the hydrodynamic injector of Zagatto et al. [7] is based on commutation, the sliding parts make this injector prone to clogging and wear when it is used for slurry injections;

- Carrero et al. [9] constructed a time-based injector which can also be characterized as HI. However, during the injection cycle sample supply and the flow in the reaction coil are stopped, therefore in the case of slurry samples deposition of particles could occur.

To be able to design FIA systems with automated direct injections of slurry samples, data are needed on the reproducibility of the injections and the dispersion behavior of the sample plug. In literature [5] only some data on the combined effects of slurry injections, slurry transport, digestion and detection of some specific components are available. This study is part of a project to derive design rules for the automated analysis of solid samples e.g. sludge, sand particles and coal, with a minimum of off-line sample pretreatment. This paper reports the development of two HI injectors. Reproducibility of the injections is an important factor, therefore a simple system to test the reproducibility of slurry injections is used. Besides the injector, the system consists of a coil to create some dispersion and a detector to perform direct turbidimetric detection of the particles. The detector was home-made and based on the lightemitting diode detector described by Worsfold et al. [10]. The advantage of this detector above others is the fact that the detector itself does not contribute to the dispersion of the sample plug [11]. Because the injections are automated the slurries have to be pumped, unlike the systems in which manual injection takes place. A valveless piston pump was used to handle the slurries instead of the peristaltic pumps that are normally used in FIA. To prevent the tubing from clogging large internal diameter tubing (1.5 $\mathrm{mm}$ ) was used. This has some negative effect on the overall dispersion and detection limit, but when demands in this area are not too high, large diameters can be used [12]. The investigated slurries consist of ion exchange particles in water; the particle size distribution was 75 to $150 \mu \mathrm{m}$. The results of the slurry injections were compared with dye injections.

\section{Experimental}

\subsection{Equipment and system control}

A Gilson Minipuls 2 peristaltic pump was used for pumping the carrier solution. Because the flexible tubing of the peristaltic pump suffered from clogging and wear when the investigated slurries were pumped, a valveless piston metering pump (Fluid Metering, type RHOCKC-LF) was used in this case. This pump could handle slurries well and none of the problems mentioned occurred. The valveless pumping is accomplished by the synchronous rotation and reciprocation of the piston in the cylinder bore. One pressure and one suction stroke were completed per cycle. A duct (flat portion) on the piston connected the cylinder ports alternately with the pumping chamber, i.e., one port on the pressure portion of the pumping cycle and the other one on the suction cycle. Sample loop, coils and connecting lines were made of $1.5 \mathrm{~mm}$ i.d. PTFE tubing.

The hereafter described injectors were based on multitube solenoid pinch valves (Cole-Parmer, H98301-22). These valves contained two tubes, one of them was normally open and the other was normally closed. The silicone tubing was closed by pinching and had an internal diameter of $1.6 \mathrm{~mm}$. However, in the open position the tube was still 


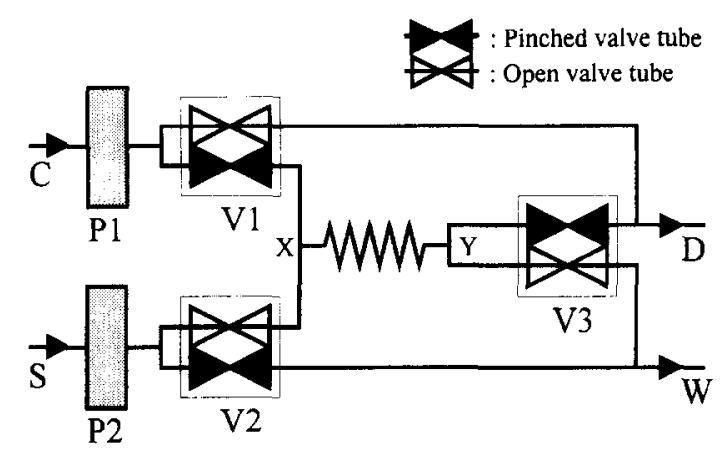

Fig. 1. Load position of the volume-based injector. S, sample; C, carrier; W, waste; D, to detector; P1, peristaltic pump; P2, valveless piston pump; V1, V2 and V3, solenoid multitube pinch valves; $\mathrm{XY}$, injected sample volume.

partly pinched which reduced the actual internal diameter to an opening of approximately $0.4 \mathrm{~mm}$ by $2 \mathrm{~mm}$. This opening was prone to clogging when slurry was pumped through. Therefore the housing of the tubes in the valves was reamed resulting in an opening of $1 \mathrm{~mm}$ by $2 \mathrm{~mm}$ in the open position. After this adjustment no more clogging occurred and although the silicone tubing was soft no particles got stuck to the wall of the tube at the point of pinching.

The detector was home-built and basically a onechannel version of the LED photometric detector described by Worsfold et al. [10]. The main components were an ultra-bright LED (660 nm) and a silicon photodiode with an integral current/voltage converter and amplifier (Radio Spares 308-067). Measurements took place perpendicular to the 1.5 $\mathrm{mm}$ i.d. PTFE tubing, the width of the lightbeam was approximately $1.5 \mathrm{~mm}$.

A program written in $C$ was used to control valve switching, light intensity of the LED, detector offset (baseline adjustment) and data acquisition (up to 100 $\mathrm{Hz}$ ). The computer hardware consisted of an IBM compatible PC (486/66 MHz), a Keithley interface card (DAS-1600) and a home-made passive DA/AD interface.

\subsubsection{Volume-based injector}

The volume-based hydrodynamic injector was based on a combination of three multitube solenoid pinch valves. Fig. 1 shows the load position of the volume-based injector. In this position sample was rinsing the sample loop $x y$ and was discharged to waste. Carrier was flowing directly through a reaction coil to the detector. When the valves were switched the trapped sample volume was propelled by the carrier stream and transported through the coil to the detector. The valves were computer controlled and switched simultaneously.

\subsubsection{Time-based injector}

Fig. 2 shows the time-based injector. P1 is a peristaltic pump, $\mathrm{P} 2$ and $\mathrm{P} 3$ have to pump slurry and are therefore valveless piston metering pumps. The order of the flow-rates was $P 2>P 1>P 3$. These flow-rates can be chosen in such a way that a constant sample supply at both the load and the inject situation is ensured. In the load position sample was transported from the sample supply towards the detector by pump P3. A small part of the sample stream and all of the carrier solution were pumped to waste by $\mathrm{P} 2$, because the flow-rate $\mathrm{P} 2>\mathrm{P} 1$. This situation was maintained for a number of seconds, so a fixed volume of sample was separated when the valve was switched to the inject position and the sample plug was propelled further to the detector. By changing the time of loading, different sample volumes could be established. At the inject position the connection between $a$ and $b$ was rinsed continuously with carrier solution (because flow-rate $\mathrm{P} 1>$ P3) to avoid contamination of the next sample. The position of pump P3, between the injector and the

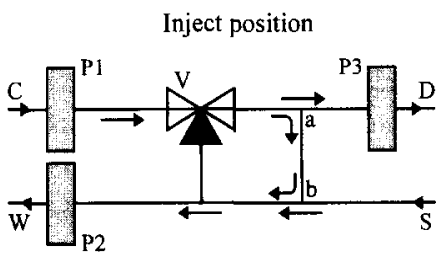

Fig. 2. Operating principle of the time-based injector. S, sample; C, carrier; W, waste; D, to detector; P1, peristaltic pump; P2 and P3, valveless piston pump; $\mathrm{V}$, pinch valve. 
detector, is not common in FIA but this has no significant effect on the reproducibility of the injections.

\subsection{Chemicals}

All solutions were prepared in Millipore Q2 water and all chemicals were of analytical grade (Merck). A dye solution, further referred to as dye, was prepared by dissolving bromocresol green in a 0.01 $\mathrm{M}$ disodium tetraborate solution. The slurry samples consisted of a spherical ion exchanger Dowex 50WX8 100-200 mesh (75-150 $\mu \mathrm{m})$, further referred to as Dowex, in water.

The Dowex particles are suspended in water and during the experiments stirred vigorously in order to maintain a homogeneous slurry. In this work, stabilizing surfactants were not used for the slurry; this is an area of further investigation.

\subsection{Measurement procedures}

\subsubsection{Volume-based injections}

The flow-rate of the sample delivery pump P2 was $8 \mathrm{ml} / \mathrm{min}$. The carrier flow-rate controlled by $\mathrm{P} 1$ was in all cases set to $7 \mathrm{ml} / \mathrm{min}$, except for the calibration measurements with dye, these were performed at a carrier flow-rate of $4 \mathrm{ml} / \mathrm{min}$. A load time of $30 \mathrm{~s}$ was used to rinse and fill the 1-ml sample loop. After the injector a 3-m coil transported the sample plug towards the detector. $\lambda$ was $0.1(\lambda$ is the aspect ratio, i.e., tube diameter/coil diameter). A relatively long coil was used to create a residence time similar to that of an on-line pretreatment unit [1], as will be used in the future. At all experiments, the data sample frequency was set to $90 \mathrm{~Hz}$.

\subsubsection{Time-based injections}

The actual flow-rates for the time-based injections are for pump P1: $8 \mathrm{ml} / \mathrm{min}, \mathrm{P} 2: 9 \mathrm{ml} / \mathrm{min}$ and P3: 7 $\mathrm{ml} / \mathrm{min}$. These flow-rates ensured a constant sample supply of $8 \mathrm{ml} / \mathrm{min}$ and a rinsing flow of $1 \mathrm{ml} / \mathrm{min}$ in the inject position between $a$ and $b$ in order to avoid contamination of the next sample. The load time was set to $10 \mathrm{~s}$. This means that, with a flow-rate of pump P3 of $7 \mathrm{ml} / \mathrm{min}$ and considering the volume between $a$ and $b$, the injected sample volume was approximately $1 \mathrm{ml}$. The coil between
$P 3$ and the detector had a length of $3 \mathrm{~m}$, as in the case of volume-based injections.

\subsection{Data handling}

Raw peak data are smoothed by means of wavelet transformation [13-15]. Peak data were convoluted with the Symmlet 8 wavelet function and high frequency noise was eliminated by filtering the wavelet coefficients. After an inverse wavelet transformation the peak data were smoothed and ready for further calculations. The peak characteristics were calculated as follows: the baseline and the standard deviation of the baseline were determined by calculating the mean value of the detector response during $10 \mathrm{~s}$ before the injection took place. After the sample passed the detector, baseline and standard deviation were calculated again. The beginning of the peak was located at the first data point which had a value higher than the first baseline plus three times the standard deviation of the baseline. The peak end was defined as the first data point of which the value was higher than the baseline after the peak plus three times the standard deviation, starting from the end of the data interval of an injection run. The peak area was calculated between the peak start and the peak end with Simpson's rule. The location of the peak top was determined with a Savitsky-Golay filter. This method fitted a curve through 7 successive datapoints of which the middle one had the highest value of the smoothed data. The exact location of the top was calculated by using the first derivative of this curve and with the location of the top of the peak the peak height could be determined.

\section{Results and discussion}

\subsection{Volume-based injector}

\subsubsection{Reproducibility of injections}

The reproducibility of injections performed with the volume-based injector was tested with injections of $40 \mathrm{mg} / 1$ dye and with a slurry sample of 15 $\mathrm{mg} / \mathrm{ml}$ Dowex. Eight injections were done in both cases. To characterize the peaks smoothing of the raw data had to take place. Peak area and peak height of smoothed data were evaluated. The inverse 
Table 1

Results of dye and slurry injections with the volume-based injector $(n=8)$

\begin{tabular}{lllll}
\hline Sample & $\begin{array}{l}\text { Peak height } \pm \text { SD } \\
\left(10^{-3} \text { abs }\right)\end{array}$ & $\begin{array}{l}\text { RSD } \\
(\%)\end{array}$ & $\begin{array}{l}\text { Peak area } \pm \text { SD } \\
\left(10^{-3} \text { abs s }\right)\end{array}$ & $\begin{array}{l}\text { RSD } \\
(\%)\end{array}$ \\
\hline Dye & $8.68 \pm 0.08$ & 0.9 & $228.4 \pm 0.9$ & 0.4 \\
Dowex & $6.93 \pm 0.08$ & 1.2 & $76.1 \pm 1.4$ & 1.8 \\
\hline
\end{tabular}

wavelet transformation with 7 levels was found to be the best for eliminating noise. The results are depicted in Table 1. The relative standard deviation of the slurry peaks is slightly worse compared to the dye peaks but better than $2 \%$.

Fig. 3 shows typical raw data signals of a dye (3A) and a slurry injection (3B). In order to compare the shapes and fluctuations of the peaks, both were performed with the same carrier flow-rate. The raw slurry peak is very 'noisy'. This noise is no system or electronic noise as can be seen when the data are compared with the raw data of a dye peak. The data sample frequency was $90 \mathrm{~Hz}$. With a flow-rate of 7 $\mathrm{ml} / \mathrm{min}$ and an internal diameter of $1.5 \mathrm{~mm}$, the average velocity of the particles is approximately 60 $\mathrm{mm} / \mathrm{s}$ so with the detector lightbeam width of 1.5 $\mathrm{mm}$, each particle is measured at least 2 times. Therefore, the signal accurately represents the passage of the slurry through the detector. The fluctuations in the raw peak data are caused by the inhomogeneity of the slurries passing the detector. This inhomogeneity is inherent to the relatively small number of particles a slurry consists of and the discrete nature of slurry particles passing the detector compared to the extent of homogeneity of a dye solution.

Fig. 3C shows the raw signal of a slurry signal

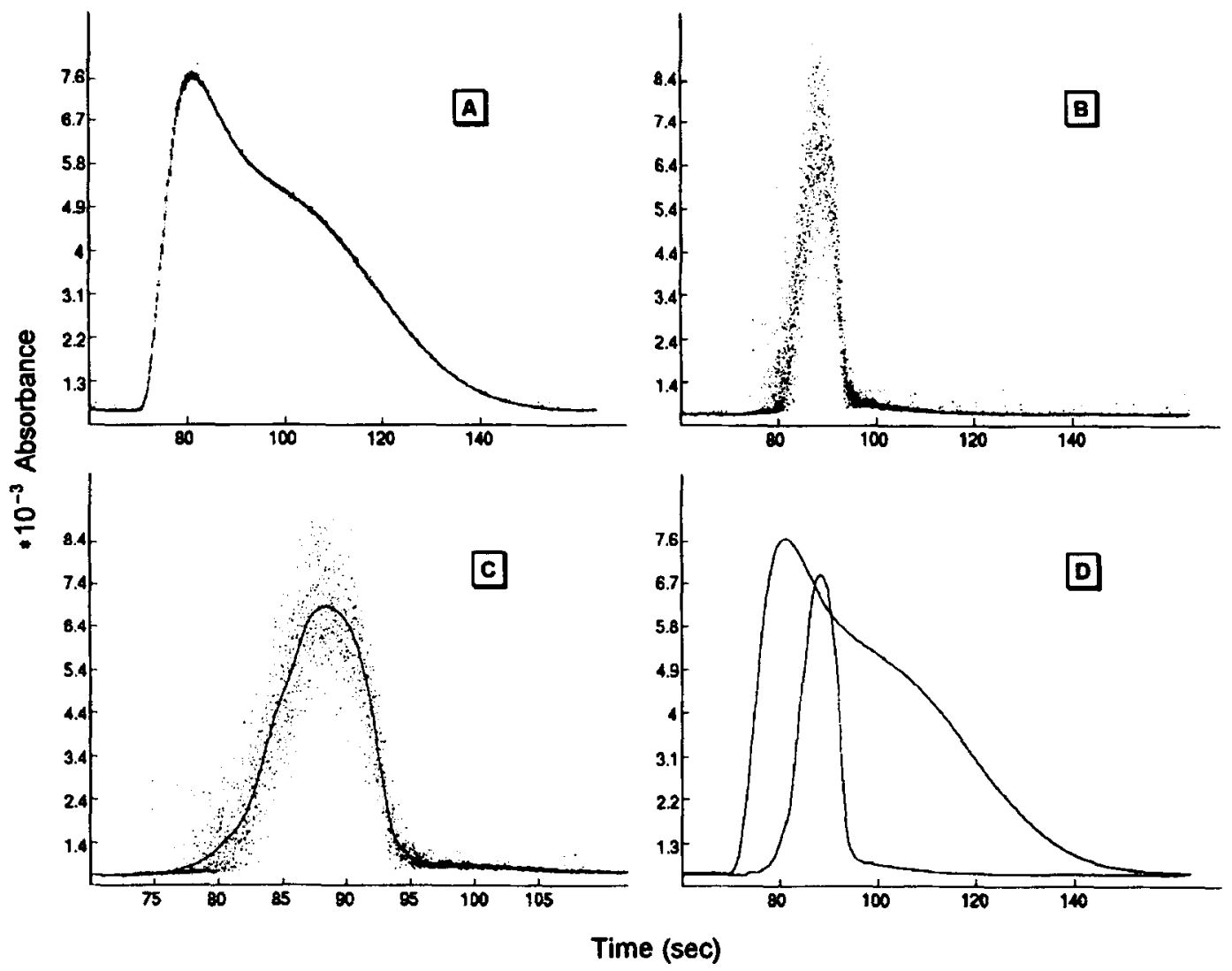

Fig. 3. Peaks of dye and slurry injections. flow-rate: $7 \mathrm{ml} / \mathrm{min}$, sample volume: $1 \mathrm{ml}$, time of injection: $30 \mathrm{~s}$, dye: $35 \mathrm{mg} / 1$, slurry: 15 $\mathrm{mg} / \mathrm{ml}$. (A) Raw dye peak; (B) raw Dowex peak; (C) Dowex peak, raw data and smoothed; (D) smoothed peaks. 
and the smoothed peak in more detail. Seven levels were used for the inverse wavelet transform. The smoothed peaks of both the dye and the slurry signal can be seen in figure 3D. The odd shape of the dye peak is due to the high flow-rate in combination with the relatively large i.d. of the tubing. At the appearance of the plug at the detector the dispersion is controlled both by convection and diffusion. When lower flow-rates or larger coil lengths (or, with the same residence time, smaller internal diameters) are used, the diffusion component will become dominant and therefore the peak shapes are more Gaussian [16]. We proved this experimentally for lower flowrates. Lower flow-rates in order to compare both peaks, however, cannot be used for slurries, because in that case particles tend to stay behind in the coil. Therefore the flow-rate of $7 \mathrm{ml} / \mathrm{min}$ was chosen; no effect on the reproducibility of the dye peaks could be observed. Fig. 3D clearly shows a difference in peak shape between the dye and slurry sample. The slurry peak shows less dispersion and has a different appearance time. These effects are a topic of further research.

\subsubsection{Calibration}

Calibration was carried out by using a series of seven dye concentrations between $2 \mathrm{mg} / \mathrm{l}$ and 60 $\mathrm{mg} / 1$ of bromocresol green. The results in Table 2 indicate a linear detector response for the peak area in this concentration range. The same was done for seven slurry concentrations from $5 \mathrm{mg} / \mathrm{ml}$ to 30 $\mathrm{mg} / \mathrm{ml}$ of Dowex particles in water. A linear calibration line could be obtained here as well (Table 2). The relatively high slurry sample concentration of 30 $\mathrm{mg} / \mathrm{ml}$ did not cause any blockages or other problems as reported elsewhere [1].

Table 2

Calibration constants of dye and slurry samples. Dye: $2-60 \mathrm{mg} / \mathrm{l}$; Dowex: $5-30 \mathrm{mg} / \mathrm{ml}$

\begin{tabular}{llcl}
\hline Sample & $\begin{array}{l}\text { Slope } \\
\text { (abs s ml/mg) }\end{array}$ & $\begin{array}{l}\text { Intercept } \\
\text { (abs s) }\end{array}$ & $\begin{array}{l}\text { Correlation } \\
\text { coeff. }\end{array}$ \\
\hline Dye & 10.3 & 0.003 & 0.9999 \\
Dowex & 0.0044 & -0.004 & 0.9995 \\
\hline
\end{tabular}

Table 3

Results of dye and slurry injections with the time-based injector $(n=8)$

\begin{tabular}{lllll}
\hline Sample & $\begin{array}{l}\text { Peak height } \pm \text { SD } \\
\left(10^{-3} \text { abs }\right)\end{array}$ & $\begin{array}{l}\text { RSD } \\
(\%)\end{array}$ & $\begin{array}{l}\text { Peak area } \pm \text { SD } \\
\left(10^{-3} \text { abs s }\right)\end{array}$ & $\begin{array}{l}\text { RSD } \\
(\%)\end{array}$ \\
\hline Dye & $3.39 \pm 0.07$ & 2.0 & $134.1 \pm 2.2$ & 1.6 \\
Dowex & $9.73 \pm 0.29$ & 3.0 & $119.6 \pm 1.9$ & 1.6 \\
\hline
\end{tabular}

\subsection{Time-based injector}

\subsubsection{Reproducibility of injections}

The results are depicted in Table 3 . Here both experiments were performed with a carrier flow-rate of $7 \mathrm{ml} / \mathrm{min}$. The time of injection was $10 \mathrm{~s}$, so the sample volume was slightly more than $1 \mathrm{ml}$. The concentration of the dye was $20 \mathrm{mg} / 1$ and the concentration of the slurry sample $20 \mathrm{mg} / \mathrm{ml}$. The reproducibility of the time-based injection seems to be slightly worse compared with the volume-based injections. This is probably (partly) due to the working principle of the valveless piston pump which is used for the metering of the sample volume. Only $30 \%$ of the stroke time of the piston carrier/sample was actually propelled. This means that if the timing of the valve switching is not exactly synchronized with the stroke of the metering pump (which was the case because the stroke rate of the pump was only approximately 6 strokes per second) one propulsion interval can be missed partly or totally.

This resulted in a slightly less reproducible sample volume compared to the volume-based injections. However, the relative standard deviation of the peak area was still less than $2 \%$.

\section{Conclusion}

The proposed manifolds for the automatic injection of slurry samples in FIA are capable of reproducible injections of slurries containing up to 30 $\mathrm{mg} / \mathrm{ml}$ Dowex particles. The volume-based injections are slightly more reproducible, but the timcbased injector seems to be an interesting alternative because of the flexibility in sample volume. Turbidimetric detection with the LED detector has proved to be useful for direct checking of the reproducibility of 
slurry injections, without any contribution to the dispersion of the sample plug. The turbidimetric detection with high data sample frequency shows major differences in peak shape and signal fluctuations between dye and slurry samples due to the dispersion behavior and the discrete nature of particles.

\subsection{Further applications}

An on-line sample pretreatment unit will be added to the system to separate absorbed ions of interest from the injected solid particles. Dowex particles are excellent ion-exchangers and can be loaded with known concentrations of specific ions. Therefore Dowex will be used to create synthetic slurries for simulation and calibration purposes. In order to derive design rules for the automated analysis of solid samples with FIA, the effect that manifold and operational changes have on the slurry behavior will be investigated and modeled.

\section{References}

[1] S.J. Haswell and D. Barclay, Analyst, 117 (1992) 117.

[2] M. de la Guardia, V. Carbonell, A. Morales-Rubio and A. Salvador, Talanta, 40 (1993) 1609.
[3] T. Gou and J. Baasner, Talanta, 40 (1993) 1927.

[4] R. Martinez-Avila, V. Carbonell, A. Salvador and M. de la Guardia, Talanta, 40 (1993) 107.

[5] P. Vinas, N. Campillo, I. Lopez Garcia and M. Hernandez Cordoba, Anal. Chim. Acta, 283 (1993) 393.

[6] J. Ruzicka and E.H. Hansen. Anal. Chim. Acta, 145 (1983) 1.

[7] E.A.G. Zagatto, O. Bahia $F^{\circ}$, M.F. Giné and H. Bergamin $F^{\circ}$, Anal. Chim. Acta, 181 (1986) 265.

[8] J. Ruzicka and E.H. Hansen, Flow Injection Analysis, 2nd edn., Wiley, New York, 1988, p. 276.

[9] P. Carrero, J.L. Burguera, M. Burguera and V. Rivas, Talanta, 40 (1993) 1967.

[10] P.J. Worsfold and J.R. Clinch, Anal. Chim. Acta, 197 (1987) 117.

[11] I.C. van Nugteren, E. Hoogendam, M. Bos and W.E. van der Linden, Anal. Chim. Acta, 239 (1990) 245.

[12] K.A. McGowan and G.E. Pacey, Anal. Chim. Acta, 214 (1988) 391

[13] M.A. Cody, Dr. Dobbs J., 17 (1992) 16.

[14] W.H. Press, Wavelet transforms, Harvard-Smithsonian Center for Astrophysics Preprint, no. 3184, 1991.

[15] M. Bos and E. Hoogendam, Anal. Chim. Acta, 267 (1992) 73.

[16] J.T. Vanderslice, K.K. Stewart, A.G. Rosenfeld and D.G. Higgs, Talanta, 28 (1981) 11. 